\title{
Reflective abilities of nursing students: A thematic analysis of reflection journals
}

Serah Wanjiru Wachira, Anne Kagure Karani, Samuel Kimani, Irene Gacheri Mageto

School of Nursing, University of Nairobi, Kenya

Received: September 7, 2021

Accepted: November 29, $2021 \quad$ Online Published: December 10, 2021

DOI: $10.5430 /$ jnep.v12n5p1

URL: https://doi.org/10.5430/jnep.v12n5p1

\begin{abstract}
Objective: Reflective writing is consistently linked to improved clinical decision-making. However, analyzing the journals to evaluate the reflective abilities of nursing students is scanty locally. This study aimed to assess the reflective skills of undergraduate nursing students.

Methods: A qualitative thematic content analysis using the Lasater Clinical Judgment Evaluation Rubric was used to assess the reflective abilities of 33 undergraduate nursing students in 138 journal entries. Guided by Gibb's reflective model, the students documented their experiences during a clinical attachment at a National Referral Hospital in Kenya between February and August 2018. Data coding and thematic linking were done using NVIVO version 11.

Results: Reflective abilities differed across gender and to some extent across years of study. Most participants were more likely to notice the deviation from the norm, whether patient-related or health care environment-related. Moreover, they demonstrated the ability to respond to the situation, self-evaluate, and develop action plans for future encounters. However, the majority struggled with interpreting findings.

Conclusions: Gender differences exist in the way nursing students reflect. Most nursing students focus on describing the situation rather than developing solutions. There is, however, an indication of developing reflective abilities across the year of study.
\end{abstract}

Key Words: Kenya, Nursing, Nursing students, Reflection journals, Reflective abilities, Undergraduate

\section{INTRODUCTION}

Reflection denotes the practice of gaining new knowledge from one's experiences and interpreting what was known before through the eyes of current experiences to inform engagements in the future. ${ }^{[1]}$ Reflective writing involves the documentation of one's insights about a particular occurrence. When students use reflection journals, the expressions of their experience over time help them develop critical thinking skills because they commit to improvement by identifying gaps in what they did. ${ }^{[1,2]}$ The journal becomes a tool of self-evaluation and an assessment of how one relates to others. ${ }^{[3]}$
Reflective writing effectively shares knowledge among nurses on their clinical experiences, which enhances knowledge transfer in future events. ${ }^{[4]}$ Writing reflections by student nurses has been linked to improved patient care and theory to practice integration, says Karimi et al. ${ }^{[2]}$ When students document their learning experiences, they can pick their learning needs and later refer to that documentation as a learning tool in the future encounter. ${ }^{[5]}$ Lasater and Nielsen ${ }^{[6]}$ alluded to the fact that reflection equips the student nurses to analyze the care given to a client and expand their clinical judgment abilities. Moreover, Barksby and colleagues ${ }^{[7]}$ state that analyzing reflection work can help infer learning.

*Correspondence: Serah Wanjiru Wachira; Email: serahkiarie@ gmail.com; Address: School of Nursing, University of Nairobi, Kenya. 
A study conducted among the second-year and third-year nursing students by Silvia et al. ${ }^{[8]}$ to identify the effect of reflective journaling showed that clinical experiences for nursing students were improved when reflective practice writing was used as a clinical learning strategy. The students were able to develop a questioning mind on their experience, which helps them improve in how they handle similar situations in the future and share with their peers to learn from their mistakes or experiences. There is consensus among researchers that reflections increase proactive decision making and help the students take responsibility for their learning process. $^{[9-11]}$

Differences in the way students reflect exist across gender, although this is an area that has not been explored significantly in literature. A study to examine nursing students' clinical experiences as documented in reflection diaries found the female students to be more reflective. The female students focused more on patient care, while their male counterparts concentrated on their personal learning experience and organizational operations. ${ }^{[12]}$ In another study, the female students were keener to operate within their scope of practice motivated by fear of making mistakes, especially in situations where the client showed deterioration despite treatment. ${ }^{[13]}$ Moreover, Via Clavero and others ${ }^{[14]}$ identified the gender differences among nurses, with the male nurses more likely to prioritize decision-making rather than client outcome and the practical aspects of care. Furthermore, on the other hand, the female nurses are more concerned about the progression and consequence of client care.

The use of reflective writing in nursing education is scanty in sub-Saharan Africa. There is no documented local study that has attempted to analyze the way students reflect or their level of reflection. There is a need to explore its use and how it can influence students' ability to integrate their theory to practice in a resource-constrained clinical setting.

\section{MethodS}

\subsection{Aims}

This study aimed to evaluate the reflective abilities of nursing students and their differences across gender and year of study.

\subsection{Design}

This study was the qualitative part of a mixed-method study to evaluate the efficacy of various clinical teaching tools in improving clinical judgment skills of student nurses during a clinical placement at a National Referral Hospital.

\subsection{Sample and participants}

The participants were 33 undergraduate nursing students (22 females: 67\%, 11 males: 33\%) in their second year (19: $58 \%$ ) and third year of study (14: 42\%). They were drawn from a Public University. The study was carried out in Kenya between February to August 2018.

\subsection{Data collection}

The students submitted one journal entry per week during a 4-8 weeks medical-surgical clinical placement. The documentation was guided by Gibb's reflective cycle to enhance consistency. Before commencing the clinical practicum, the students went through a 2-day training on documenting their reflections. A sample reflection was provided as a reference guide. A preceptor trained in reflective writing gave them feedback on their write-ups weekly. After the clinical practicum, the researcher collected the student journals for analysis.

\subsection{Ethical consideration}

The National Commission for Science Technology and Innovation (NACOSTI) approved the study and the Kenyatta National Hospital-University of Nairobi (KNH-UoN) Ethics and Research Committee. Each of the participants signed a consent form. The student journals were coded to enhance anonymity.

\subsection{Data analysis}

Coding, transcribing, and analyzing the journal narratives were done using NVIVO version 11 software. Thematic content analysis of the journal entries to identify the reflection abilities of student nurses was done using the Lasater Clinical Judgement Rubric (LCJR) themes as a guide. The LCJR thematic areas include noticing, interpreting, responding, and reflecting. ${ }^{[15]}$

The aspects of 'Noticing' measurements were stated as the ability of the student to make a focused observation, recognize deviation from the usual pattern, and questioning. 'Interpreting' dimensions included the ability of the student nurse to make sense of the data obtained and prioritize. Responding dimensions showed how the student communicates, confidence, clarity, proper planning, and skillfulness. Finally, the reflecting aspect was described as the ability to self-analyze and develop action plans that show commitment to improvement. ${ }^{[15]}$ According to Lasater and Nielsen, ${ }^{[6]}$ the reflection abilities of the student nurse can be used by faculty to infer clinical judgment development.

The researcher used the Lasater Clinical Judgment Evaluation Rubric (LCJR) to construct the thematic areas of focus. The Lasater CJ model was developed based on the work of

ISSN 1925-4040 E-ISSN 1925-4059 
Tanner. ${ }^{[16]}$ This framework has been validated in multiple studies and different countries ${ }^{[17-19]}$ with similar findings of the tool possessing a high construct validity and interrater reliability. It has also been applied in analyzing students' reflections for reflective abilities ${ }^{[20]}$ and as a way to structure the reflections. ${ }^{[21,22]}$

\subsection{Limitations}

The participants in this study were drawn from one University during a clinical attachment in a public hospital. The findings may not be generalizable to all nursing students and clinical settings. There is a need to carry out similar studies among nursing students in the private sector and other clinical settings to compare findings.

\section{Results}

\subsection{Participant characteristics}

The participants were 33 nursing students with a mean age of $21.50 \pm 1.34$ years. They were in their second or third year of study in a 4-year undergraduate nursing program from a public University School of Nursing in Kenya. The majority of the students were female $(n=22 ; 66.7 \%)$. Those in the third year of study were the majority $(\mathrm{n}=19 ; 57.6 \%)$ compared to their second-year counterparts $(n=14 ; 42.4 \%)$.

The journal entries were thematically analyzed for reflective abilities, using the four domains of the 2007 Lasater Clinical Judgement model as themes, which include; noticing, responding, reflecting, and interpreting. The majority of the participants saw a deviation from average, whether patientrelated or health care environment-related. The majority struggled with interpreting their findings but could reflect on their practice and somehow respond to the situation at hand (see Figure 1). In the noticing domain, recognizing deviation from the normal findings was more prominent, followed by focused observation with minimal information seeking. In the responding domain, being skillful was dominant, with students stating they either learned a new skill or mastered an old skill. In the reflection domain, commitment to improving and evaluating the situation was evident. The ability to interpret findings to make sense of the data and prioritize was only observed in a minority of the students.

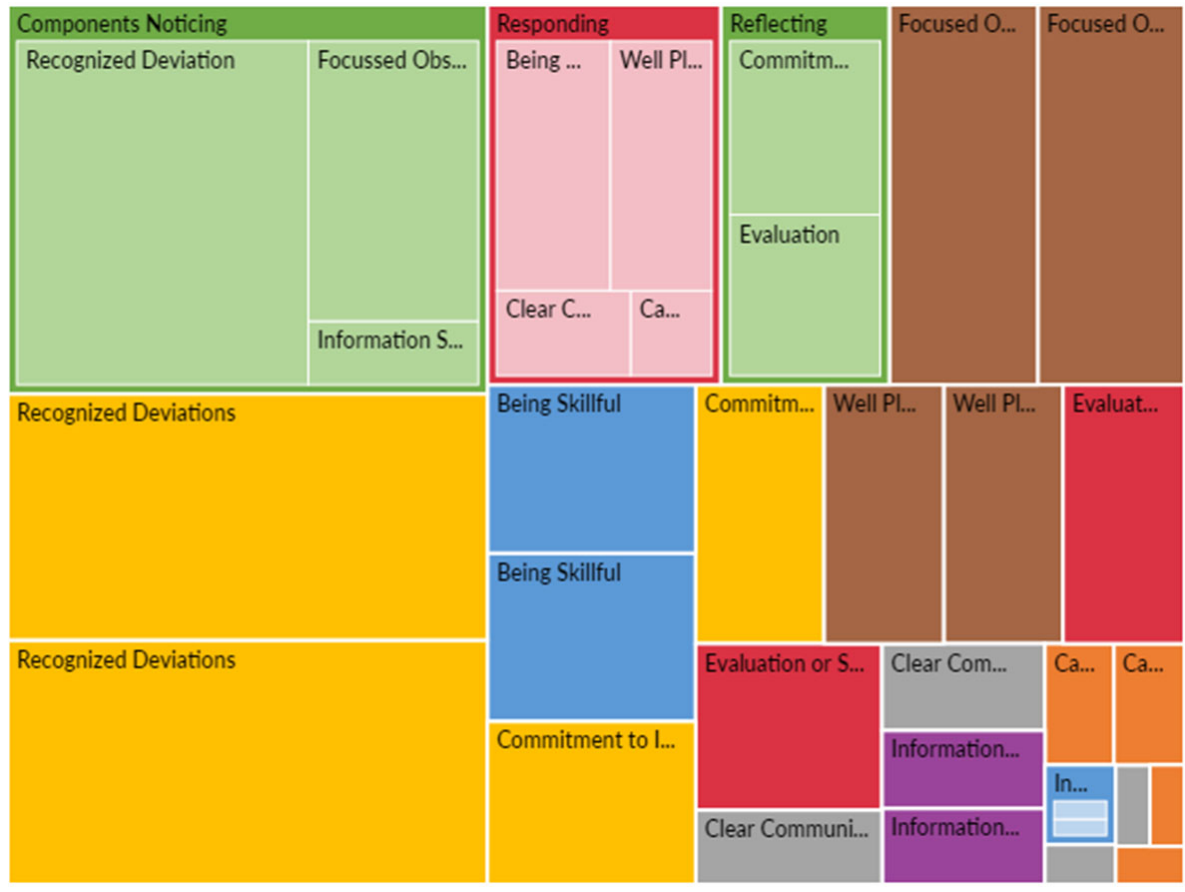

Figure 1. Themes and sub-themes spread in a hierarchy chart based on nursing students journal entries

\subsection{Theme one: Component noticing}

The thematic area of component noticing includes recognizing findings that deviate from routine, focused observation, and information seeking. The researcher did further analysis to identify the reflective abilities based on gender and year of study attributes. The findings showed that the female student nurses demonstrated a better ability to notice the change from the norm whether they were second-year or in the third year of study compared to their male counterparts (see Figure 2). Information seeking attribute was more associated with the third-year nursing students comparatively. 


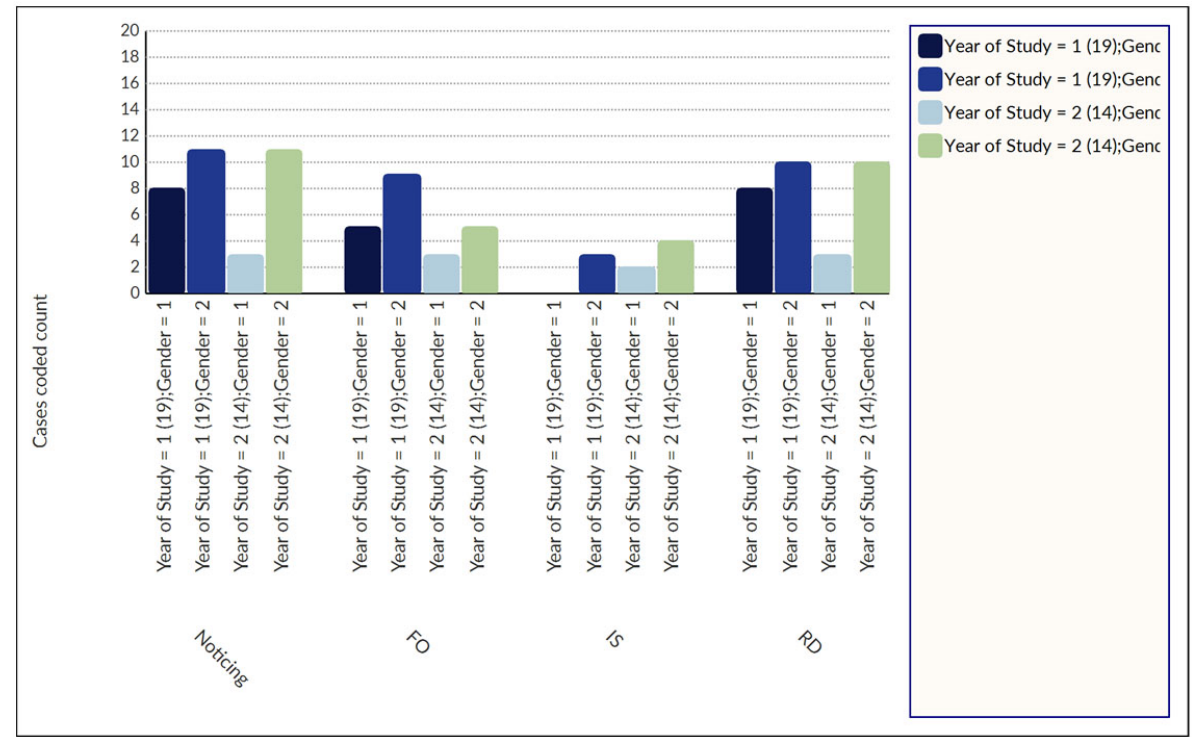

Key: FO: focused observation; IS: Information seeking; RD: recognize deviation; Gender 2-Female; Gender 1Male; Year of study 1- second year; year of study 2-Third year

Figure 2. Cross-tabulation on component noticing theme and sub-themes according to year of study and gender attributes

\subsection{Theme two: Interpreting}

The second theme was interpreting the situation, whether patient or otherwise. The sub-themes included making sense of the data and prioritizing the data. This attribute was not as evident compared to the others. A few male first-year students demonstrated this attribute, focusing on making sense of the data. The female students prioritized whether they were in their second year or third year of study (see Figure 3).

\subsection{Theme three: Responding}

The responding attribute was evident among the female nursing students regardless of their year of study. In their second year of study, the students focused on being skillful, while their third-year counterparts concentrated on ensuring their interventions were well planned. Of importance is the fact that the second-year female students identified being calm and confident as an essential attribute in their reflections (see Figure 4).

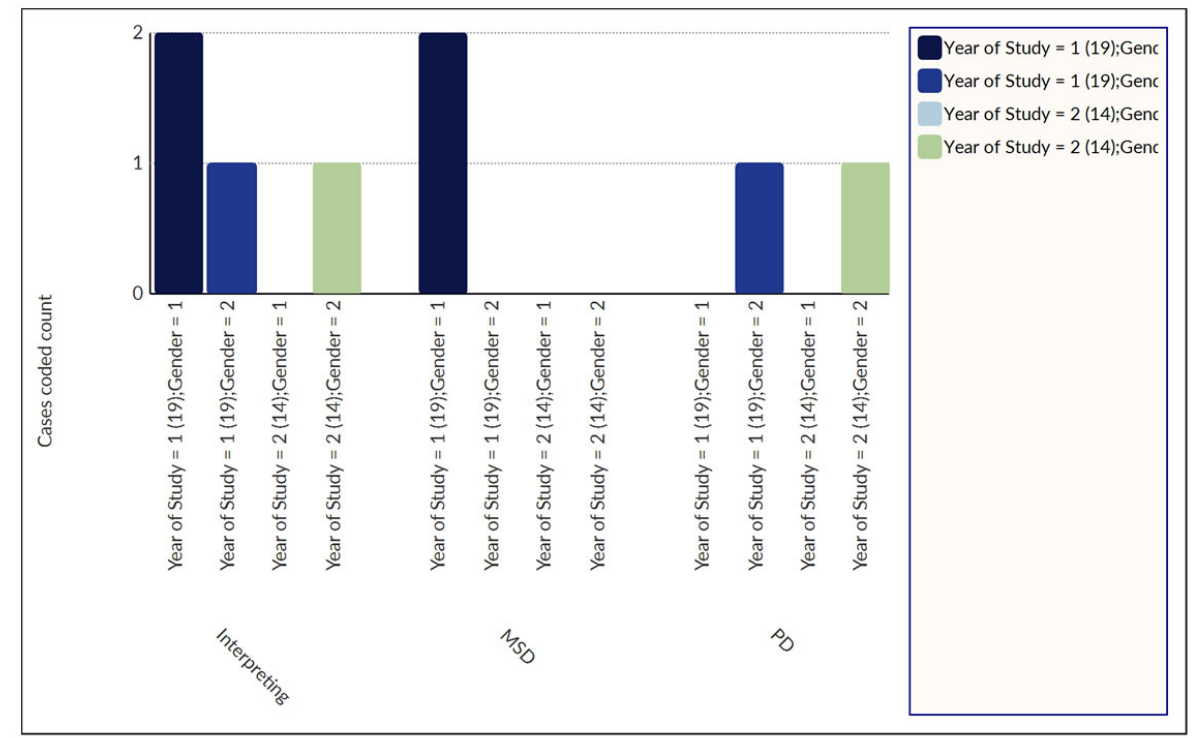

Key: MSD: Making Sense of the Data; Prioritizing Data; Gender 2-Female; Gender 1-Male; Year of study 1second year; year of study 2-Third year

Figure 3. Cross-tabulation on interpreting theme and sub-themes according to year of study and gender attributes 


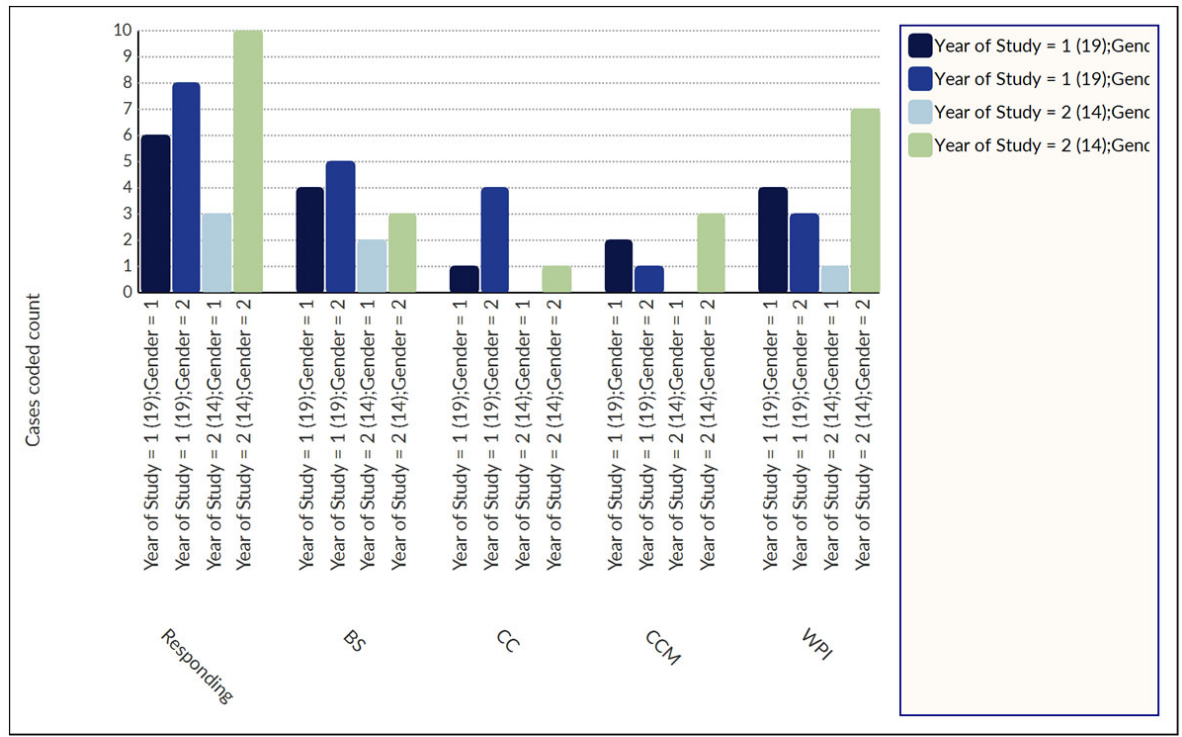

Key: BS: Being skillful; CC: clear communication; CCM: Calm Confident Manner; WPI: Well Planned Intervention; Gender 2-Female; Gender 1-Male; Year of study 1- second year; year of study 2-Third year

Figure 4. Cross-tabulation on responding theme and sub-themes according to year of study and gender attributes

\subsection{Theme four: Reflecting}

This theme was represented by the ability of the students to develop action plans that identified their gaps and how they would work towards improvement, as well as evaluating how they handled the issue based on what should be. The female nursing students were identified as possessing the attribute of reflection compared to their male counterparts regardless of the year of study. Commitment to improving qualities was evident in the female students across the year of study, while self-evaluation was identified among the female students in their third year of study (see Figure 5).

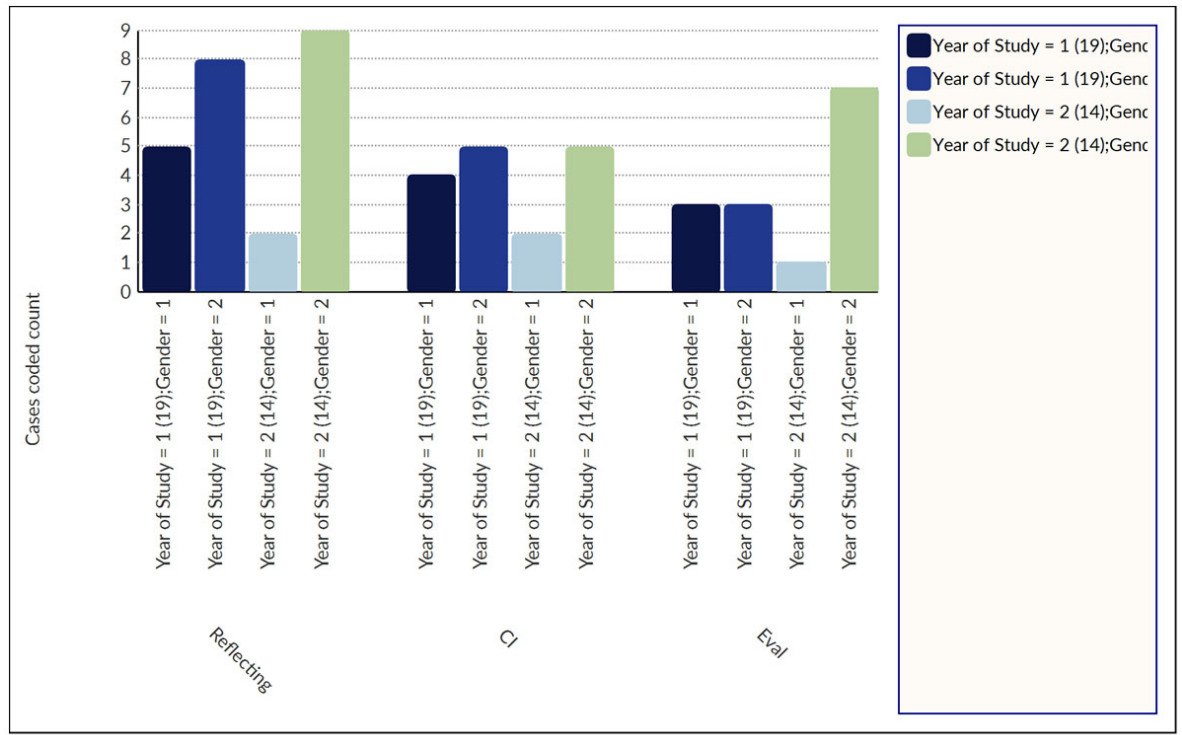

Key: CI: Commitment to improve; Eval: Evaluation; Gender 2-Female; Gender 1-Male; Year of study 1- second year; year of study 2-Third year

Figure 5. Cross-tabulation on reflecting theme and sub-themes according to year of study and gender attributes

\section{Discussion}

This study found that most of the participants noticed a deviation from regular, whether it was patient-related or health care environment-related. However, they struggled with interpreting their findings but could reflect on their practice and somehow respond to the situation at hand. The results 
confirm that the students' reflections were more based on component noticing and minimal on prioritizing and making sense of the data. This finding concurs with Bjerkvik and Hilli, ${ }^{[23]}$ who found that majority of the student reflections were mainly descriptive.

However, the majority analyzed how they responded to the situation and committed to working on their skill gaps through appropriate action plans. This finding aligns with Sivia et al., ${ }^{[8]}$ who found that students engaged in reflections developed a questioning mind and improved their response in handling similar situations in the future. Vreugdental and Spek ${ }^{[18]}$ conversely found that the student scored higher in interpreting and responding than noticing and reflecting, which contrasts with this study's findings. The students noticed deviation from ordinary and reflected on their practice compared to their ability to interpret and respond to the situation.

This study found disparities in the way male and female students reflect. The majority of the female students possessed the attribute of recognizing deviation from the norm, prioritizing, responding in a calm, confident manner, and self-evaluation as an attribute of reflection. On the other hand, the male students focused on making sense of the data or interpreting their findings. The finding aligns with Gonzalez-Garcia et al., ${ }^{[12]}$ who found a difference between how male or female students reflect on their practice. As identified in this study, the female students focused on patient care and were more emotional and reflective. On the other hand, the male students focused more on their learning and quality of care delivery. However, there was evidence that both cohorts improved their understanding and abilities in delivering personalized patient care.
Regarding the level of study, the third-year students were more likely to seek further information, develop well-planned interventions and commit to self-improvement. The attributes, in this case, demonstrate higher-order reflective abilities developing as the students navigate through their training. ${ }^{[6]}$ It is also evident that higher-order skill acquisition occurs over time as the novice student nurses navigate the clinical environment ${ }^{[24]}$ and can be enhanced by timely, appropriate faculty or preceptor feedback. ${ }^{[25]}$

\section{Conclusion}

The majority of nursing students focus more on describing the events at hand without interpreting the occurrence, as has been found in similar studies; however, there is an indication of higher-order reflective abilities of self-awareness and commitment to improving as action plans. These attributes demonstrate developing clinical judgment skills regardless of the year of study.

The reflective abilities of student nurses differ across gender. The female students focus on responding to the situation while their male counterparts focus on making sense of the data. Analysis of how students reflect should be through the lens of gender differences in the way people express themselves and interpret occurrences in the clinical setting.

\section{ACKNOWLEDGEMENTS}

This study acknowledges the contribution of Teddy Gafna, the statistician, in providing the software for data analysis. Special thanks to the students who participated in this study.

\section{CONFLICTS OF INTEREST Disclosure}

The authors declare that there is no conflict of interest.

\section{REFERENCES}

[1] Jarvis MA, Baloyi OB. Scaffolding in reflective journaling: A means to develop higher-order thinking skills in undergraduate learners. International Journal of Africa Nursing Sciences. 2020 Jan 1; 12: 100195. https ://doi.org/10.1016/j.ijans. 2020.100195

[2] Karimi S, Haghani F, Yamani N, et al. A Qualitative Inquiry into Nursing Students' Experience of Facilitating Reflection in Clinical Setting. Wong LP, editor. The Scientific World Journal. 2017 Apr 4; 2017: 6293878. PMid:28474003 https://doi.org/10.1155/20 $17 / 6293878$

[3] Tashiro J, Shimpuku Y, Naruse K, et al. Concept analysis of reflection in nursing professional development. Japan Journal of Nursing Science. 2013; 10(2): 170-9. PMid:24373440 https : //doi.org/ $10.1111 / \mathrm{j} .1742-7924.2012 .00222 . \mathrm{x}$

[4] Chirema KD. The use of reflective journals promotes reflection and learning in post-registration nursing students. Nurse Educ Today. 2007 Apr; 27(3): 192-202. PMid:16815600 https : //doi .org/10 $.1016 /$ j.nedt .2006 .04 .007
[5] Epp S. The value of reflective journaling in undergraduate nursing education: a literature review. Int J Nurs Stud. 2008 Sep; 45(9): 1379-88. PMid:18325522 https://doi.org/10.1016/j.ijnurstu. 200 8.01 .006

[6] Lasater K, Nielsen A. The Influence of Concept-Based Learning Activities on Students' Clinical Judgment Development. J Nurs Educ. 2009 Aug 1; 48(8): 441-6. PMid:19681533 https ://doi.org/10 .3928/01484834-20090518-04

[7] Barksby J, Butcher N, Whysall A. A new model of reflection for clinical practice. Nurs Times. 2015 Sep 19; 111(34-35): 21-3.

[8] Silvia B, Valerio D, Lorenza G. The reflective journal: A tool for enhancing experience-based learning in nursing students in clinical practice. In 2012.

[9] Kennison MM. The evaluation of students' reflective writing for evidence of critical thinking. Nurs Educ Perspect. 2006 Oct; 27(5): 269-73.

[10] Mahlanze HT, Sibiya MN. Student nurses' Perceptions on the writing of reflective journals as a means for personal, professional, and 
clinical learning development. Health SA Gesondheid. 2017 Dec 1; 22: 79-86. https://doi.org/10.1016/j.hsag.2016.05.005

[11] Naber J, Markley L. A guide to nursing students' written reflections for students and educators. Nurse Education in Practice. $2017 \mathrm{Jul}$; 25: 1-4. PMid:28437690 https://doi .org/10.1016/j.nepr.2 017.04 .004

[12] González-García M, Lana A, Zurrón-Madera P, et al. Nursing Students' Experiences of Clinical Practices in Emergency and Intensive Care Units. Int J Environ Res Public Health. 2020 Aug; 17(16): 5686. PMid:32781646 https://doi .org/10.3390/ijerph17165686

[13] Fernández-Feito A, Basurto-Hoyuelos S, Palmeiro-Longo MR, et al. Differences in professional values between nurses and nursing students: a gender perspective. International Nursing Review. 2019 Dec 1; 66(4): 577-89. PMid:31378939 https://doi .org/10.111 $1 /$ inr. 12543

[14] Via Clavero G, Sanjuán Naváis M, Martínez Mesas M, et al. [Identity of gender and intensive care: influence of masculinity and femininity in the perception of nursing care]. Enferm Intensiva. $2010 \mathrm{Sep}$; 21(3): 104-12. PMid:20688266 https://doi .org/10.1016/j .enfi.2 009.11 .004

[15] Lasater K. Clinical Judgment Development: Using Simulation to Create an Assessment Rubric. JNE. 2007 Nov 1; 46(11): 496-503. PMid:18019107 https://doi.org/10.3928/01484834-20071 101-04

[16] Tanner CA. Thinking like a nurse: a research-based model of clinical judgment in nursing. J Nurs Educ. 2006; 45(6): 204-11. PMid:16780008 https ://doi .org/10.3928/01484834-20060 601-04

[17] Shin H, Gi Park C, Shim K. The Korean version of the Lasater Clinical Judgment Rubric: A validation study. Nurse Education Today. 2015 Jan 1; 35(1): 68-72. PMid:25034956 https ://doi .org/10 $.1016 / \mathrm{j}$. nedt .2014 .06 .009
[18] Vreugdenhil J, Spek B. Development and validation of Dutch version of Lasater Clinical Judgment Rubric in hospital practice: An instrument design study. Nurse Educ Today. 2018 Mar; 62: 43-51. PMid:29289636 https://doi.org/10.1016/j.nedt.2017.12 .013

[19] Yang F, Wang Y, Yang C, et al. Improving clinical judgment by simulation: a randomized trial and validation of the Lasater clinical judgment rubric in Chinese. BMC Med Educ. 2019 Jan 14; 19(1): 20. PMid:30642320 https://doi.org/10.1186/s12909-019-145 4-9

[20] Dillard N, Sideras S, Ryan M, et al. A collaborative project to apply and evaluate the clinical judgment model through simulation. Nurs Educ Perspect. 2009 Apr; 30(2): 99-104.

[21] Lusk Monagle J, Lasater K, Stoyles S, et al. New Graduate Nurse Experiences in Clinical Judgment: What Academic and Practice Educators Need to Know. Nurs Educ Perspect. 2018 Aug; 39(4): 201-7. PMid:29746356 https://doi.org/10.1097/01. NEP.0000000 000000336

[22] Hines CB, Wood FG. Clinical Judgment Scripts as a Strategy to Foster Clinical Judgments. J Nurs Educ. 2016 Dec 1; 55(12): 691-5. PMid:27893904 https://doi.org/10.3928/01484834-20161 114-05

[23] Bjerkvik LK, Hilli Y. Reflective writing in undergraduate clinical nursing education: A literature review. Nurse Education in Practice. 2019 Feb 1; 35: 32-41. PMid:30660960 https ://doi .org/10.1 016/j.nepr.2018.11.013

[24] Benner P. Educating nurses: a call for radical transformationhow far have we come? J Nurs Educ. 2012 Apr; 51(4): 183-4. PMid:22476535 https ://doi .org/10.3928/01484834-20120 402-01

[25] Nielsen A, Stragnell S, Jester P. Guide for reflection using the clinical judgment model. J Nurs Educ. 2007; 46(11): 513-6. PMid:18019109 https://doi.org/10.3928/01484834-20071101-06 